\title{
Preservation of Cultural Heritage via Education of Children, Utilizing Visual Communication: Persepolis as a Case Study
}

\author{
Parnaz Goodarzparvari' ${ }^{1}$, Francisco Carlos Bueno Camejo ${ }^{2}$ \\ ${ }^{1}$ Department of Graphics, Faculty of Art, Central Tehran Branch, Islamic Azad University, Tehran, Iran \\ ${ }^{2}$ Department of Art History, University of Valencia (Universitat de València), Valencia, Spain \\ Email: parnaz1981@gmail.com
}

How to cite this paper: Goodarzparvari, P., \& Camejo, F. C. B. (2018). Preservation of Cultural Heritage via Education of Children, Utilizing Visual Communication: Persepolis as a Case Study. Creative Education, 9, 141-151.

https://doi.org/10.4236/ce.2018.92011

Received: September 3, 2017

Accepted: January 10, 2018

Published: February 2, 2018

Copyright ( $) 2018$ by authors and Scientific Research Publishing Inc. This work is licensed under the Creative Commons Attribution International License (CC BY 4.0). http://creativecommons.org/licenses/by/4.0/

\begin{abstract}
Focusing on the next generations as the owners of the heritage, development of the educational approach for children is an important issue which would assist the preservation of cultural affairs. Provision of the possibilities by which children can get familiar with their cultural treasures would support the cultural sustaining and maintaining approaches of the society while this chain would deliver the cultural values more effectively. Among several approaches, visual communication as the unique language which can be understood and utilized by every nation has been considered as an educational approach for children to promote their knowledge on the value of cultural heritage. Considering the fame and importance of Persepolis, it has been aimed as case study and different visual communicating procedures have been proposed for education of Persian student on this world heritage, while in some cases, the possibilities and limitations have been discussed.
\end{abstract}

\section{Keywords}

Visual Communication, Children, Education, Persepolis, Cultural Heritage

\section{Introduction}

Cultural heritages are knows as one of the most important backing and identity of the culture of a society while their conservation is a critical domain. Cultural heritages as the source of the most traditions which are maintained and spread inside a society, are the reflecting means for culture preservation, presentation and delivering, while they are the most influencing treasures, known necessary to convey the culture to the later generations (Heritage, 2012). A global glance 
on cultural heritages would demonstrate that many of these heritages have faced an increasing number of troubles and threats caused by unexpected natural occurrences, environmental parameters, social situation and also some human interventions. Preservation of cultural heritages against them is a complicated task for which several educational and practical approaches are needed. Several researches have revealed the role of education in this way and by analyzing the different age levels children and youth have been introduced as the most important sector to be educated (Fleer \& Robbins, 2007; Bamford, 2006). This part of society is known as the directors of future trends who will play a notable role in sustaining of heritage. In order to explore the culture aspects of a society, there is an indispensable need of children to communicate with the environment by which the future stakeholders of the culture would become familiar with it. The usual relationship of children with cultural heritage sights is predominantly peaceful, but sometimes some damages have happened by them especially on historical painting and sculptural heritages which are unprotected located in open space. There are many approaches and forms of communication by which the children would become familiar with the necessity of the conservation of cultural heritage (NACCCE, 1999). In many countries a culture course is conducted since primary school which lets the young students to acquire useful knowledge of some global and local cultural heritages. This knowledge would encourage their interest on conservation as well. Visual communication that is the nonverbal form of the education approaches has been considered as a powerful mean for development of the educational plans in children for conservation of cultural heritage (Heeter, 1999; Barnard, 2013; Cole, Sugioka, \& Lynch, 1999). In this way, visual communication would inspire pioneering creative art and imagination in children while it can motivate them via its incredibly increasing participation in the daily life aspects. In this article the different aspects of visual communication strategies for education of children will be discussed while Persepolis as a famous Persian cultural heritage monument will be the case to be studied. It is mentionable that cultural heritage is conceptually divided into tangible and intangible heritage. Persepolis is a tangible cultural heritage and thus the approaches discussed in this paper would be more compatible for this category of the heritages. Persepolis is one of the ancient cities of Iran, which for many years has been the capital of the glorious kingdom of Iran during the Achaemenid Empire. In this ancient city there is a palace called Persepolis, which was built during the reign of Darius the Great, Xerxes and Artaxeres I, and has been around for 200 years. On the first day of the New Year, many groups from different countries representing satraps or governorates were gathered together in diverse pretexts in Persepolis and presented their gifts to the Shah. In 518 BC, the construction of Persepolis as the new capital of the Achaemenids began at Pars. The founder of Persepolis was great Darius, after which his son Xerxes and his grandson, Ardeshir I, expanded to expand it. Many of the available knowledge of the Achaemenid background and their culture are availa- 
ble due to stones and flowers that have been carved in these palaces and on the walls and plaques. Sumner estimated that the plain of Persepolis, consisting of 39 residential buildings, had 43,600 inhabitants during the Achaemenid period. According to historians, Alexander the Great, Macedonian ruler, attacked Iran in $330 \mathrm{BC}$, invading Persepolis to the fire and probably destroyed a large part of Achaemenid books, art, and art. Nevertheless, ruins of this place are still under way and archeologists confirm the ruins of the signs of fire and invasion. This historic site since 1979 is one of the recordings of Iran's UNESCO World Heritage Site.

\section{Environmental Graphics and Its Impact}

Young children are exposed to the cultural heritages by the possibility of immediate observations, meetings and experiences of the environmental graphics and art works from their surroundings. Considering their visual observation from urban atmosphere, monuments, constructions and buildings that they meet during their daily path or those environmental designed works which can been seen during city walks and art works and paintings in museums, their daily life can also be considered as a potential possibility for educational aims (Gutierrez, Frischer, Cerezo, Gomez, \& Seron, 2007). Each meeting with an environmental element involves some form of communication. The encounter with the environmental graphic design elements which are adopted according to work of art as a specific example of cultural heritage can stimulate the communication more effectively (Sabnani, 2005; Christopoulos \& Gaitatzes, 2009). Recent movements in development of environmental graphic design strategies conformed to the cultural heritage articles have affected the children through the process of experiencing and receiving, a nonverbal artistic vision of them. In case of monuments, children are most often passive observers and it is helpful to encourage them to actively communicate with the heritage. Urban design elements, park statues, and building facades, inspired of the style and conformation of Persepolis would allow abolishing the usual distance between the monuments and the child during the sight visit. Previous investigations have revealed that directed visits are most commonly manifested in not sneaking and touching the artwork. Thus, an idea is to describe the environmental elements, designed according to the structure of Persepolis and let them to participate in intervening and interpreting of Persepolis through its reflection in environmental graphics. The advantage of such methodically designed indirect communication with Persepolis as a unique architectural complex, apart from its introduction, also would manifest itself in encouraging children's artistic creativity and imagination through visual dialogue with selected examples of the sights and signs, motifs, etc. For many students, more frequent encounters with cultural heritage, images and reproductions, especially in architectural and urbanism activities would provide useful imagination of the heritage. Figure 1 shows the entrance of a hotel in Kish Island, Iran which has been constructed according to the style of Persepolis. 


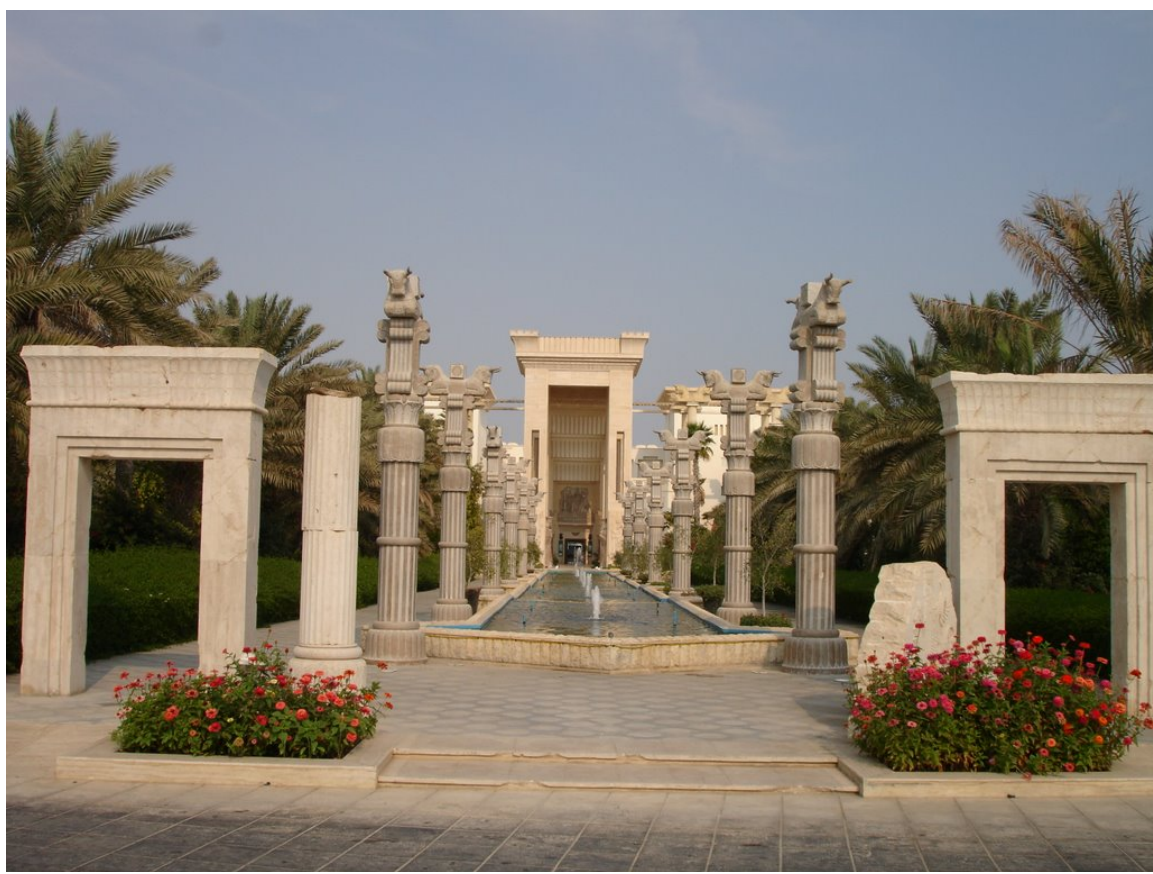

Figure 1. Entrance of a hotel in Kish Island, Iran.

An idea is to design the modern atmosphere of the city by the ideas inspired of the ancient style. City halls, bus and subway stations, shopping malls, etc. are some of the media to be considered for cultural heritage presentation via environmental graphics. Figure 2 shows a famous motif of Persepolis, reconstructed in a subway station wall.

Children can be educated during their daily life, even by residing in a hotel during a trip or passing by a subway station while being back from school. Nowadays, environmental design which has been inspired from ancient architecture and urban design is a new trend in Iran. The facade and interior design of the buildings is a typical example of this inspiration. On the other hand, the urban services are also designed by the symbols obtained from traditional Persian culture. The architectural style and the motifs of Persepolis are the source of idea for these two fields, respectively.

\section{Teaching Visual Communication for Encouraging the Creativity and Imagination}

While communicating with children, a useful plan for development of strategies for conservation of the cultural heritage is to increase their level of creativity during art education. Several scientific investigations and some artistic efforts have tried to determine the origin of imagination and creativity. Approaches to these phenomena would be different depending on the origin area of scientific or artistic interest of an individual researcher (Addison, 2000). Creativity is understood differently from a country to a country and from culture to culture. Different perspectives on what is "creative", caused the value of creativity to be a culture-relative factor. An idea is to consider creativity as a cultural production 


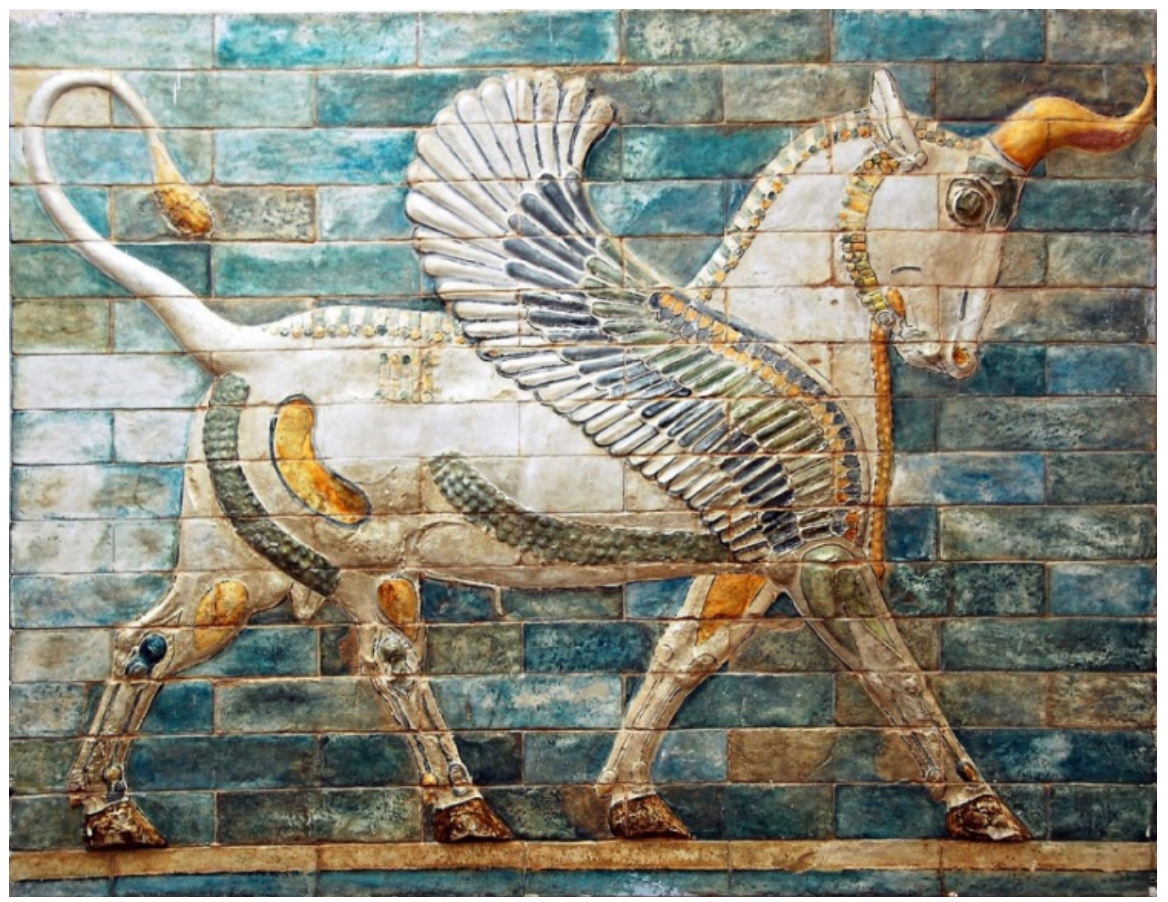

Figure 2. A subway stations, designed by Persepolis motif.

and problem solving common tool to all cultures, but that what counts as problem solving, the content is different in each culture. Perhaps also because imagination represents freedom in relation to reality, freedom that is interpreted as self-sacrifice, thus these phenomena have been remained unclear (Cheow, 2008). A welcome experience of comfort in some creative activity ensures the development of imagination and creativity that can be stimulated and then realized in another area of learning and action. Creative imagination is the activity in which the superb power of interconnecting and unifying the different artistic or scientific experiences, together with correlated performances and insights, the spiritual activity in which, as methodically. The common strategy for development and extension of creativity in children is to allow the freedom of thought and creation, considering it a prerequisite for stimulating imaginative thinking. In this way, borderless allowance for provision of the requirements in the domain of imagination would be known as the path of thinking and the motivating all creativities to enable the productive sense for them. Therefore, leaving the fear of failure as well as the concern about the outcome, i.e. the evaluation and assessment of fine arts, enables students to experience the experience of comfort during the methodically designed process of artistic expression (Cross-Curriculum Dimensions). In this way, for an approach of rational thinking, education is based, neglecting the power of the image as a mirror of imagination. Explanations on the original structure of the Persepolis before the Alexander's attack together with brief presentation of the epistemological information on that era would also extend the imagination of the students. Recent art campaigns relying on the traditions of Achaemenes era is a good example of this idea. Figure 3 
shows a simulated image of a Persian soldier's face by visual communication and illustration.

On the other hand, visual reconstruction of those damaged parts of the cultural heritage sight which have been recorded in children's mind.

A new strategy in Iran is the formation of a Heritage School (Established on September 2012) with the aim of holding workshops for the training of cultural heritage for children and adolescents. In the strategy of this school it has been stated that pointing out that the need to educate the heritage of citizens in developed countries has been a source of attention for many years, and there have been many activities in this area, public education in museums and historical sites, with creative teaching methods, is an inseparable part in many of the world's museums have been featured. But an important part of the citizens of any society is its children. Children and adolescents have had many activities in the field of heritage education in European and American countries, and children are also keen on visiting historic sites. Also, the training programs conducted for this age group in the historic sites have led to a boom in these places.

In Iran, despite the diverse activities that have been carried out in the field of general heritage education, the recurrent course has not been followed. This lack is observed, especially in the field of childhood and adolescent age education. However, over the years, there have been individuals and groups who have been concerned about this kind of education and have done some activities, but the importance and importance of teaching the heritage to the child is much greater than the range of activities carried out. For this reason, the Heritage School has devoted a large part of its activities to teaching children and adolescents, and is trying to fill the gap with the help of cultural heritage experts.

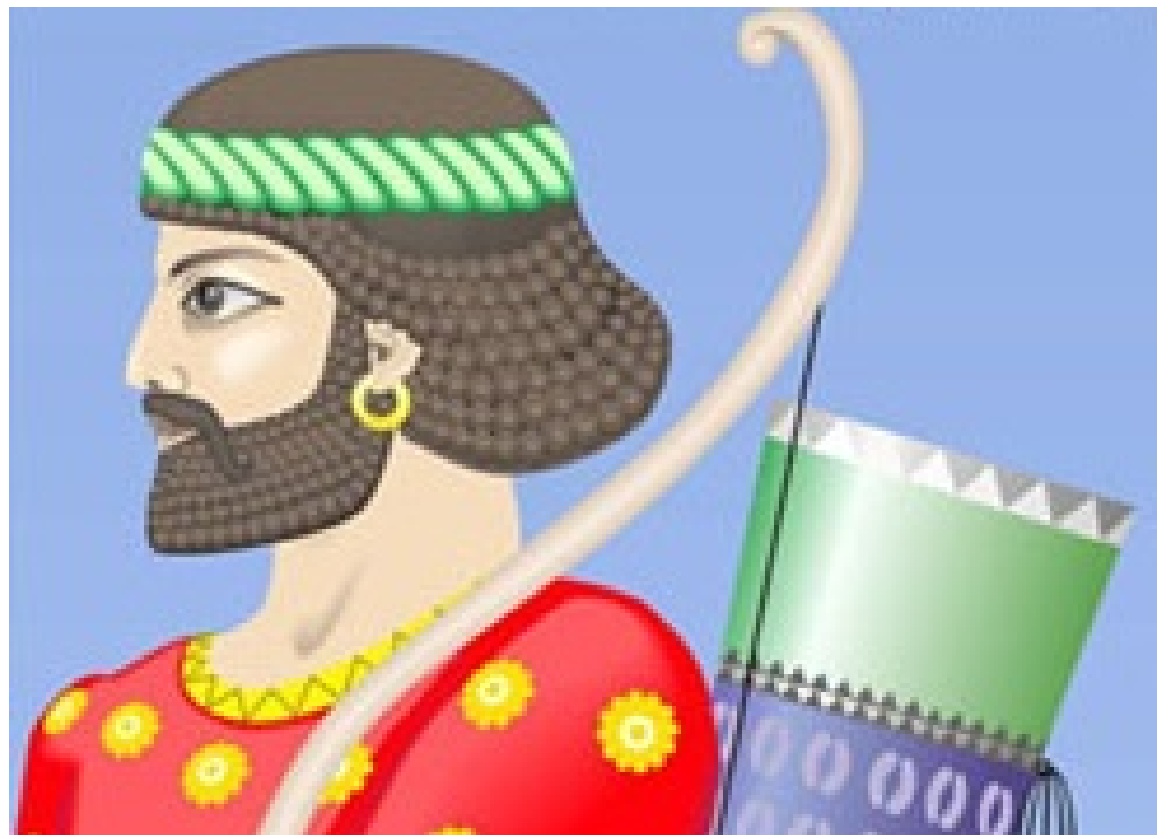

Figure 3. Persian soldier of Achaemenes era. 


\section{Communication in the Teaching of Cultural Heritage by Graphics}

Nowadays for teaching of any topic, understandable transmission of visual messages from and artwork together with those obtained from visual reality to students is the key point. It takes place through a complex process of aesthetic experience and aesthetic transfer in which emotional and rational components are exchanged. One of the spontaneous forms of children's communication is also artistic expression. Children's visual arts are developed through the artistic tasks contained in the teaching topics defined by the curriculum, during the elementary school, passing the designed artistic education course (Madeleine \& Fleury, 2011; The Metropolitan Museum of Art). In order to explore, understand and adopt many of the key concepts of cultural heritage preservation, the student needs to communicate the topic by a visual language within teaching topics on selected examples of cultural heritage. It is necessary to know how students know about the cultural heritage that is an integral part of their environment, while allowing them to have artistic dialogue. The essence of art communication with selected examples is based on research learning, as well as the freedom of artistic interpretation. Communication with heritage on the course of fine arts is also a possibility. History course is also a good opportunity to communicate with the desired topic. In any case, the explanation on the culture and its heritages would be initiated by a teacher who would provide the graphical supporting material and tries to discuss with students, playing the role of the mediator of certain known knowledge, story and context, but also the one that starts from the student's pre-knowledge and interest in the heritage from their surroundings. Trying to increase the capabilities of the students by putting them in the situation of thinking about the value of heritages and negotiating with them, it is possible to encourage aesthetic experience together with cultural knowledge. On the other this is a reasonable way to transfer and maintains a cultural and artistic creative atmosphere within the group of children while allowing the freedom of independent imagination and description of heritage on selected visual examples.

Another recent trend is to continue the individual artistic dialogue with heritage through its interpretation or reinterpretation, utilizing graphic media i.e. different artistic interventions present in the student's artwork. The tracing of visual; communication with cultural heritage testifies to newly emerging student works that represent "new" artistic and heritage works that they are co-creators. Here is to ask them some painting, illustration and photographic tasks. The dialogue with cultural heritage or taught historical sight continues throughout the review and evaluation of student artwork by other students and teachers. This process provides new possibilities for experiencing, transferring and interpreting aesthetic messages contained in student artwork, as well as in the original visual examples of cultural heritage. This strategy seems easy initially but it is a little bit complicated procedure due to indirect communication with the heritage, how- 
ever it will promote their imagination and divergent thinking because it is based on the freedom of cultural and artistic interpretation, but also to the satisfaction and comfort of the unreachable achievement. Persepolis consists of several elements which would inspire the children for their art productions. Figure 4 shows an art work of a group of Iranian students trying to make a model of Persian motif from Persepolis.

\section{Critical Skills Training and Making the Objects Appear}

One of the most important tasks for children is to teach problem solving skills and critical skills. We have to teach the children to ask questions and then to consider hypotheses for their questions and to gather evidence to prove or disprove the hypotheses. In the final stage, according to the collected evidence, there is an analysis, inference, and conclusion. Children need to learn how to find the right answer for their questions and measure it with critical thinking.

Given the children's emotional development process according to psychologist Erik Eriksson, cultural heritage sights are appropriate places for linking information to day-to-day issues, but unfortunately, in most countries with rich cultural heritage, for many reasons, not much attention has been paid to problem-solving literature, while in addition to teaching solving skills Critical

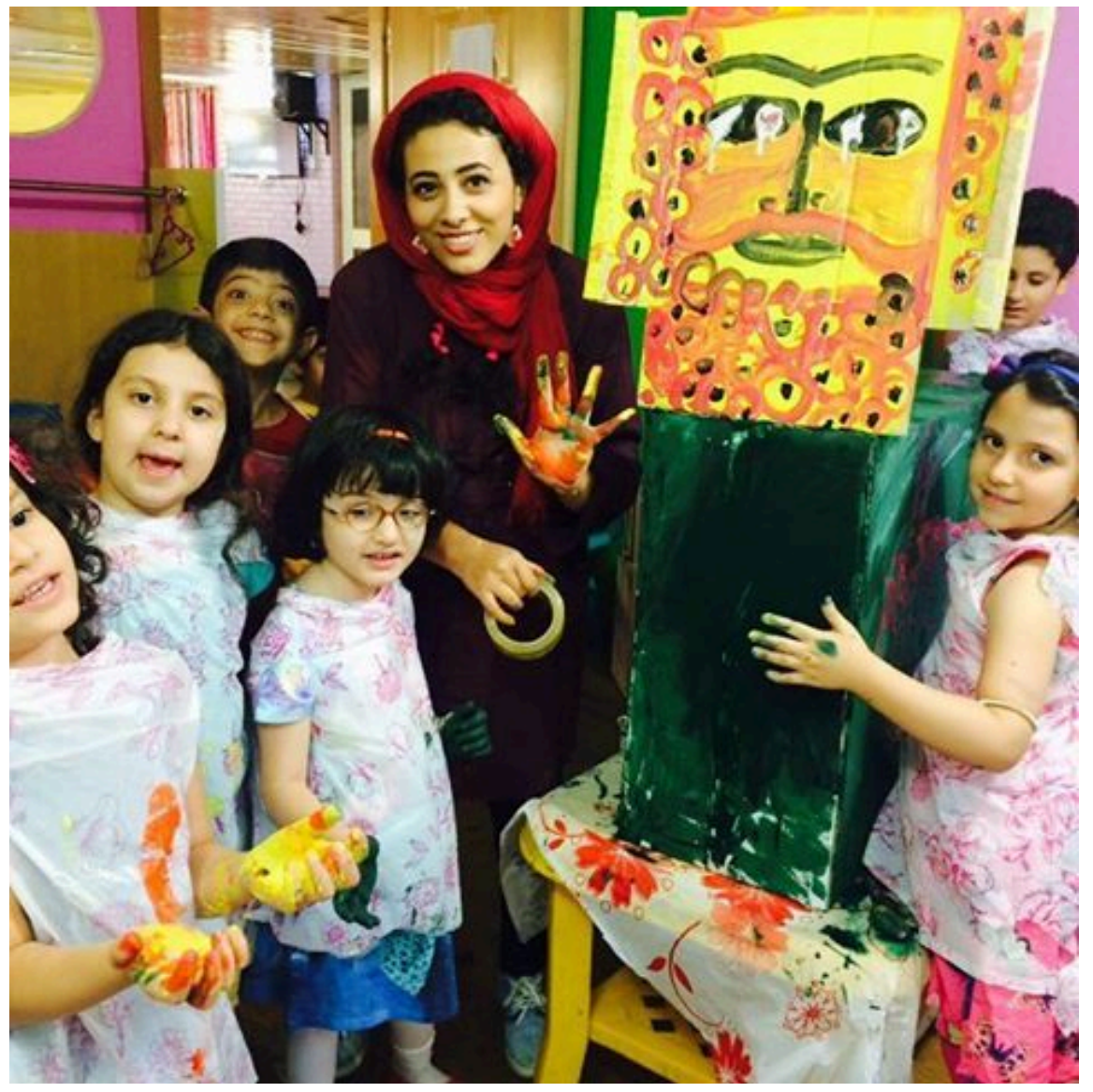

Figure 4. Persepolis motif by young students of primary school. 
Thinking and Critical Thinking, the most challenging issues of society's day can be posed to children rightly. One of the effective teaching methods is to use the elements of historical traditions associated with the heritage and to visualize objects with the characterization and characterization so that children enjoy this kind of encounter with the works and communicate with them. The book-mapping method is also useful for environments such as museums located in historic and cultural centers.

As a starting point for the realization of artistic dialogue with heritage students must be faced to some critical questions about the historical aspects of the focused heritage. Then a defined artwork will be selected by which the questions will be answered. The mechanism for answering the questions is to obtain the knowledge for development of the artwork and by this acquired knowledge the ambiguities will be more transparent. The artwork medium can be successfully used in visual and artistic research in the field of education, most often with illustrative, contextual, narrative, argumentative or demonstrative purposes. It is useful to use graphical designed artworks e.g. posters, illustrations or even infographics to teach art of culture primarily as a motivational incentive or a motif. Simultaneously and during the development of artwork, the teacher would describe the different characteristics of the monument through a motivational conversation with the students. Thus they can select one or more of the characteristics or functions of the heritage to which they feel more interested to focus on during their progress in artwork.

\section{Concluding Remarks}

Failure to respect cultural heritage, accelerated urbanization processes and the failure of architectural performance, transformation and interpolation are the most common causes of the decline of our architectural heritage as part of a national identity. During the educational process, there is a valuable opportunity to provide the approaches for students to learn about heritage and culture and to take a positive view of their value. It can almost always be an incentive for visual communication and expression. Among several approaches for education to students, visual communication was explored in this paper, emphasizing the importance of mediation, in particular, visual and visual messages from artistic works considering the outcome of education about cultural heritage. The evolution of student's skills on visual communication artwork would make an indirect dialogue with cultural heritage which would be fruitfully realized by them during learning the elements of their culture. Advantages of communication with their heritage through the reflection in graphic design artworks would manifest itself in encouraging imaginative thought and creativity through free children's visual intervention on the image of an architectural work from their environment. Among several notable Persian cultural heritages, Persepolis was selected to be investigated. It was realized that in spite of its fame and global prestige, there is a severe lack of educational plans for making the students familiar with it and 
providing the conservation approaches. However, it is desired that utilizing visual communications, students would learn something, enriching their art speech by applying key concepts points in their works, motivating towards the conservation and preventing further damage to the heritage. Further, by allowing students to explore, perceive, remember, imagine, and learn about heritage, then their image of the necessity of conservation is interpreted and redefined freely. It all would be obtained by the artistic act during which the distance between the monument and the student is tried to be abolished.

Thus it was concluded that art communication with the heritage via visual approaches and graphic design would inspire children's artistic creativity and imagination, and confront them with a uniform and stylized visual communication to which today's children are exposed as future and leading users of mass and new media. And their artwork viewpoints by observing or creating visual communication articles would initiate a justified methodical path that would make it possible for the heritage to be brought closer to students, being protected and safe, at least during such artistic educational activities. However, typical practical researches in combination with statistical evaluations are needed for the better understanding of the influence of these educative approaches.

\section{References}

Addison, A. C. (2000). Emerging Trends in Virtual Heritage. IEEE Multimedia, 7, 22-25. https://doi.org/10.1109/93.848421

Bamford, A. (2006). The Wow Factor: Global Research Compendium on the Impact of the Arts in Education. Berlin: Waxmann.

Barnard, M. (2013). Graphic Design as Communication. London: Routledge.

Cheow, Y. (2008). Deciphering Creativity: A Potential Transformation in Art and Design Classrooms in Singapore. In One Voice International Conference \& Forum for Educators San Francisco (pp. 1-28). San Francisco, California.

Christopoulos, D., \& Gaitatzes, A. (2009). Multimodal Interfaces for Educational Virtual Environments. In Proceedings of the 13th Panhellenic Conference on Informatics (PCI'09) (pp. 197-201). Corfu, Greece. https://doi.org/10.1109/PCI.2009.8

Cole, D., Sugioka, H., \& Lynch, L. (1999). Running Head: Supportive Classroom Environments for Creativity. The Journal of Creative Behavior, 33, 277-293.

https://doi.org/10.1002/j.2162-6057.1999.tb01407.x

Cross-Curriculum Dimensions. A Planning Guide for Schools. http://www.centreforglobaleducation.org/documents/Cross\%20curriculum\%20dimensi ons\%20-\%20a\%20planning\%20guide\%20for\%20schools\%20publication_tcm8-14464.p df

Fleer, M., \& Robbins, J. (2007) A Cultural-Historical Analysis of Early Childhood Education: How Do Teachers Appropriate New Cultural Tools. European Early Childhood Education Research Journal, 15, 103-119. https://doi.org/10.1080/13502930601161890

Gutierrez, D., Frischer, B., Cerezo, E., Gomez, A., \& Seron, F. (2007). AI and Virtual Crowds: Populating the Colosseum. Journal of Cultural Heritage, 8, 176-185. https://doi.org/10.1016/j.culher.2007.01.007

Heeter, C. (1999). Technology Enhanced Learning. White Paper for the Internet 2 Sociotechnical Summit, Michigan State University, Department of Telecommunication. 
Heritage (2012). 3rd International Conference on Heritage and Sustainable Development Overview, Porto, Portugal, June 2012.

Madeleine, S., \& Fleury, P. (2011). Reconstruction of Ancient Rome in Interactive Virtual Reality. In J. Al-Qawasmi, Y. Alshawabkeh, \& F. Remondino (Eds.), Proceedings of the Digital Media and Its Applications in Cultural Heritage Conference (DMACH'11) (pp. 169-183). Amman: CSAAR Press.

National Advisory Committee on Creative and Cultural Education (NACCCE) (1999). All Our Futures: Creativity, Culture and Education. http://sirkenrobinson.com/pdf/allourfutures.pdf

Sabnani, N. (2005). The Challenges of a Sleeping Giant. Design, 21, 94-105. https://doi.org/10.1162/074793605774597460

The Metropolitan Museum of Art. Museum Kids: Explore and Learn. https://www.metmuseum.org/learn/kids-and-families 